to observe psychological procedures in practice, and preferably to participate with supervision in psychological treatments.

Constraints of different placements and attachments may make it difficult to provide such practical experience at the same time as the related academic teaching.
ReFERENCES

'Royal College of Psychiatrists (1985) Working party for review of the MRCPsych: Report to the Court of Electors.

${ }^{2}$ Kopeluan, M. D. (1982) The psychiatrist learning psychology: sponge or jackdaw? AUTP Newsletter, December, 44-51.

${ }^{3}$ Fraser, D. (1984) The province of behaviour therapy. DCP Newsletter No. 46, 26-28.

\title{
Drug Abuse in the Bahamas
}

Nelson Clarke, Consultant Psychiatrist, and Michael Neville, Consultant Psychiatrist, Sandilands Rehabilitation Centre, Nassau, Bahamas

The Bahamas is a group of islands, just off the coast of Florida, extending southwards to near the island of Hispaniola. There are approximately 25 inhabited islands and numerous small islands and cays that are uninhabited. The population of the Bahamas is approximately 230-240,000. A census taken in 1980 showed that approximately $65 \%$ of the population is aged between $15-45$ years. The major industries lie in tourism and off-shore banking. The Bahamas has not always had a drug problem; the diagnostic records at the mental hospital, Sandilands Rehabilitation Centre, reveal that in the sixties drug-related admissions were negligible. In the early seventies, however, there was a rapid increase in cannabis use and at the same time the number of drug-related admissions increased. The patients were mainly admitted in acutely disturbed states which were thought to be drug psychoses caused by cannabis inhalation. There do not seem to have been many patients requesting help to stop using cannabis, and generally there has been no significant change in this pattern. The major difference is the vast increase in the quantities smoked by an individual user. In the mid-seventies, the pattern of drug use began to change in that more patients were using a number of drugs at the same time. Methaqualone enjoyed a period of popularity and was known on the street as Quaaludes, Mx or Disco Biscuit. The drug's ability to potentiate the action of alcohol made it both dangerous and alluring, as it was possible to get 'stoned' almost immediately for the price of only one drink and one pill. It was about the same time in the mid-seventies that cocaine hydrochloride began to arrive on the market in increasing quantities and start gaining in popularity. The major problems at that time were associated with druginduced psychoses, acute intoxications and occasions of violent bizarre behaviour due to the disinhibition and release of aggression caused by these drugs. One drug addict from this era, interviewed in the prison, said that a good night out was to smoke some grass, drink a Guinness stout, take a quaalude and then snort some cocaine. There is really no literature as to what effect these combinations may have on the brain. It is of interest however that very few patients were presenting for treatment of addiction, though by the late seventies a trickle had begun to come forward. Cocaine was not that plentiful and was being used by snorting, i.e. the inhalation of the finely ground white powder into the nostrils. A less popular method of use of cocaine at that time was smoking the finely ground powder as a constituent of a tobacco cigarette or mixed into the contents of a marijuana cigarette. The quantities of cocaine available on the Bahamian street market at that time were small.

The next major change in drug abuse patterns occurred around 1979 when somehow the concept of 'freebasing' cocaine was introduced to the Bahamas. The problem was not immediately apparent, cases began to surface and stories indicating the depths of this addiction began to worry us. The admission rate gradually began to increase, but cocaine was still expensive and so many people could not afford it.

Over the last three years the method of use known as free-basing has become increasingly popular, so much so that $98 \%$ of all patients seeking help with a cocaine dependence problem report free-basing as their method of use. The method involves releasing relatively pure cocaine from the hydrochloride radical, by a simple process involving the addition of an alkali such as sodium bicarbonate, dissolving both in water and heating the mixture. After cooling pure cocaine crystals are formed. The pure cocaine is then vapourised and inhaled using a variety of instruments. The most commonly used is a home-made pipe, locally referred to as a 'camoke', made by covering a glass with tinfoil, making small holes in one side, on which cigarette ash and the cocaine crystals are placed, and placing another larger hole in the opposite side, which serves as a mouthpiece. Patients report that the cocaine is now more often than not sold to them already prepared for 'free-basing'. In 1982 most of the patients admitted to psychiatric hospital for help with a cocaine dependence problem were males between the ages of 18 and 30 years and, although all social classes were represented, more than $50 \%$ of these patients were from the lower socio-economic groups.

Over 1983 and the first half of 1984 there have been a number of changes noted. Firstly, the number of patients seeking help for cocaine dependence has increased to such 
an extent that the existing facilities are totally inadequate and unable to cope, and a waiting list has been instituted. Secondly, more females are presenting themselves for treatment and rehabilitation. Thirdly, the age range of persons of both sexes presenting with cocaine dependence has widened such that persons as young as nine years of age and patients over the age of $\mathbf{4 0}$ years are becoming increasingly common. Females now constitute $15-20 \%$ of the total number of patients in treatment at any given point in time. In 198360 males and nine females were admitted to hospital for cocaine dependence. In 1984 the figures were 169 and 51 respectively. There has been no evidence to date which suggests that coca paste use occurs in the Bahamas.

The Bahamas does not produce any cocaine. It is thought that the cocaine available in the Bahamas originates from South America. The Law Enforcement Department in the Bahamas thinks that the Bahamas is used as a transshipment point for cocaine and marijuana intended for North America, and that Bahamians are involved in the trans-shipment process. Those who are involved have access to the drugs, and in some cases are paid with the drugs. It is believed that it is in this way that the drugs enter the local market. It is also thought that when drugs are deposited on any of the small numerous small islands and cays they are sometimes found by local residents. The increased availability suggests that there is perhaps increased traffic of cocaine through the Bahamas.

Linked with the changes already mentioned must be the decrease in price of cocaine on the street, and the increased quantity available. Information obtained from drug abusers in therapy suggests that the price of cocaine available on the streets has dropped considerably, to such an extent that what would have cost $\$ 100.00$ in 1980 can now be bought at $\$ 50.00$. These factors have all continued to produce quantities of cocaine that obviously shape the local patterns of usage. The most common pattern of use seen appears to be daily use of cocaine with the period of time spent using per day varying from a few hours to sometimes up to four to five hours of intermittent use. During this time it is often reported that one user may consume as much as three to four grams of cocaine.

Less commonly, people who may spend a number of days, usually two to three over the weekend, in intermittent use are encountered. Some of them report using up to 10 grams of cocaine during this period.

Most patients report that they usually congregate with friends at what are frequently referred to as free-basing parties, or at 'base' houses. However, they may also use cocaine in a solitary fashion from time to time. The development of the free-base camps is a phenomenon causing much concern to public health personnel and the police. These usually appear to be located in old abandoned buildings without proper water and hygiene facilities. People dependent on cocaine congregate at these places in the hope that cocaine will be easier to obtain, possibly free. Base camps are thought to exist on three islands primarily, Grand Bahama, Andros and New Providence.

There have been a few cases of intravenous use among cocaine dependent persons, six reported so far. This does not appear to be a popular method of use; whether this will change remains to be seen.

\section{Conclusion}

Less than a decade ago cocaine was virtually an unknown drug in the Bahamas. Over the past five years cocaine has become an extremely popular drug and there are now a growing number of Bahamians who are experiencing problems with cocaine dependence. The large quantities of the drug available, the high addiction potential of the drug, and the cheap price indicate that the problem may become worse.

The present mental health services are incapable of helping the already large (and growing) number of cocaine dependent persons seeking help. Specific services will have to be developed to help those seeking help with a cocaine dependence problem. Efforts must be intensified to prevent the spread of cocaine use; prevention strategies utilising all the available avenues, and directed at the population in general, need to be implemented. It may well be that in spite of efforts made by the law enforcement agencies to decrease the availability of cocaine, the present problem with cocaine will remain for a number of years at least.

Cocaine dependence has not been reported as a signifcant problem throughout the remainder of the Caribbean region, but the possibility exists that the problems now occurring in the Bahamas may spread to the other countries in the region. It is at this time when cocaine is still a relatively unpopular drug in the other territories that these countries must begin to implement prevention strategies.

\section{Recent Publications}

Quality Assurance Abstracts is a new abstracting bulletin which concerns quality assurance in health care, primarily within the UK. It is being produced jointly by the King's Fund Centre Quality Assurance Project and the DHSS Library, and is being published by the DHSS. It will be published bi-monthly with an annual cumulation of the author and subject indexes as a seventh issue. Each of the bi-monthly issues will contain reference to some 150 English language documents, and an author and subject index. The annual subscription price will be $£ 10.50$ or $£ 1.50$ per single issue. Subscriptions should be addressed to DHSS (Leaflets), PO Box 21, Stanmore, Middlesex HA7 1AY.

The A-Z of Welfare Benefits for People with a Mental Illness has recently been published by MIND and, as the first publication to concentrate on the benefits and allowances available to people with a mental illness, will be of help to health service users and the professionals who work with them. It costs $£ 1.00$ (post-free) and is available from the MIND Publications Mail Order Service, 4th Floor, 24-32 Stephenson Way, London NW1. 